\title{
Quantity Restrictions and Price Adjustment of Chinese Textile Exports to the U.S.*
}

\author{
Daniel Bernhofen ${ }^{\dagger} \quad$ Richard Upward ${ }^{\ddagger} \quad$ Zheng Wang ${ }^{\S}$
}

Accepted by The World Economy 12 September 2017

\begin{abstract}
The elimination of the Multifibre Arrangement (MFA) in 2005 provides an unusual opportunity to examine the effects of a trade policy shock on export prices and firm behaviour. It was massive in scale, discrete in timing and exogenous to firms and consumers in the textile industry. Since the MFA quota removal did not affect all textile products at the same time, we are able to use a difference-in-difference approach to estimate the causal effects of the MFA. Using transaction-level data from the Chinese Customs Trade Statistics over the period 2000-2006, we find that the MFA removal reduced average export prices by about $25 \%$. This fall was mainly caused by a combination of the entry of new low-price exporters and new low-price products, rather than a fall in prices of existing firm-product combinations. We also find that price reductions are twice as large for heterogeneous than for homogeneous products.
\end{abstract}

Key Words: MFA, Chinese exports, US, textile

JEL Classifications: D22, F13

\footnotetext{
*The original version of this paper was circulated as a working paper with the title "Quota as a Sorting Machine: Quantity Restrictions and Price Adjustment of Chinese Textile Exports to the U.S." (Bernhofen, Upward, and Wang, 2011). We thank Peter Neary, Kala Krishna, Eric Verhoogen, Zhihong Yu, Michele Imbruno, Lisandra Flach, Miaojun Wang, and many seminar and conference participants for their helpful comments and suggestions. Financial support from The Leverhulme Trust under Programme Grant F/00 114/AM is greatly acknowledged. All remaining errors are our own.

${ }^{\dagger}$ School of International Service, American University.

${ }^{\ddagger}$ School of Economics and Centre for Research on Globalisation and Economic Policy (GEP), University of Nottingham.

${ }^{\S}$ Corresponding author. Faculty of Business and Law, De Montfort University. Email: zheng . wang@dmu . ac .uk .
} 


\section{Introduction}

Changes in trade policy are usually gradual. In the context of a developing economy, changes in trade policy are also often accompanied by domestic policy reform. Both factors hamper causal inference of policy changes on economic behaviour. In contrast, the elimination of the Multifibre Arrangement (MFA) in 2005 provides an unusual opportunity to estimate the effects of quota removals on firm behaviour. It was massive in scale, discrete in timing and exogenous to firms and consumers. In a seminal paper Harrigan and Barrows (2009) (henceforth HB) exploit the 2005 MFA removal as a quasi-experiment to estimate the effects of quota eliminations on U.S. import prices and find evidence of quality downgrading on imports from China. Our research complements HB by examining the effects of the MFA on Chinese exporters. Using transaction-level data from the Chinese Customs Trade Statistics, we examine the impact of the MFA removal both on export quantities, volumes and prices and on the export behavior of Chinese textile firms in the U.S. market.

We first estimate the effects of quota removal on export unit values at the 6-digit product level. Using a variety of empirical specifications that employ alternative definitions for treatments and controls, we find that the MFA quota removal reduced average export prices between $18 \%$ and $36 \%$, with a benchmark estimate of $25 \%$. Our estimated price drop at the product level is consistent with the findings in $\mathrm{HB}$, albeit coming from a completely independent data source.

Our paper distinguishes itself from HB by exploiting the firm-level transaction detail nature of the data to examine the role of firm effects in the reduction of export prices following the elimination of the MFA. Specifically, we estimate the role of firm behavior by a parsimonious fixed effects approach which makes increasingly restricted price comparisons: within product, within firm and finally within specific firm-product combinations. Differences in the estimated magnitude of our key parameter reveal that a large fraction of the fall in unit values is caused by the changes in the identity of firms which were exporting products in our treatment group. Overall, we demonstrate that the inclusion of firm and product fixed effects results in a substantial 
increase in the explanatory power of the model and find that about half of the (average) fall in price resulted from a combination of new exporting firms and new exporting products, and that less than one-third of the price reduction is due to firms lowering unit values on products which they sold before and after the quota removal.

A new feature of our product-level analysis is that it allows us to examine the magnitude of the price effect by product type. Because the MFA policy change restricts the product scope of our analysis to the textile and clothing categories, the Rauch measure of product differentiation (Rauch, 1999) does not provide enough variation in our context. However, our firm-level information permits us to use firm-level price variations within a product category as a proxy for product heterogeneity. Employing this measure, we find significantly larger price drops for heterogeneous than homogeneous products. Controlling for the number of firms, the price drop for heterogeneous products is more than twice as large as for homogeneous products.

While the elimination of the MFA in 2005 was a trade policy shock that affected only the textile and textile industries, China's 2001 entry into the WTO affected its broader manufacturing sector. Examining the effect of WTO entry on Chinese export prices, Fan, Li, and Yeaple (2015) have found that a reduction of import tariffs resulted in an increase in export prices in differentiated products and an export price decrease in homogeneous products. Their finding is motivated by a theoretical model where a reduction of import tariffs reduces a firms' marginal costs, which then frees resources used for designing higher quality products. Because this dynamic story of quality upgrading takes some time, they focus on price changes over a five-year time period (2001-2006). In contrast, in our analysis import tariffs change very little, and the removal of quotas was very sudden (from December 31, 2014 to January 1, 2015). Therefore, this quality upgrading mechanism has been eliminated by construction. Instead, our findings are consistent with the well-known the well-known theoretical prediction that a quota removal will result in quality downgrading (e.g. Falvey, 1979). Taken together, Fan, Li, and Yeaple (2015) and our analysis reveal that reductions in trade barriers can have both short- and long-term effects on 
product quality.

While we worked on this research, we became aware of the work by Khandelwal and coauthors, which was published in Khandelwal, Schott, and Wei (2013, henceforth KSW). ${ }^{1} \mathrm{KSW}$ estimate the price effect of quota removals for Chinese products to all destinations, rather than just the U.S. They estimate that export prices fell by about $20 \%$ for product-country pairs which were covered by the MFA, compared to a small growth in prices for other textile product-country pairs which were not covered. Using decomposition methods, they estimate the proportion of the price drop which can be attributed to new firms and incumbents. In contrast to KSW, we focus only on Chinese exports to one specific market (the U.S) and we use fixed-effects methods rather than a decomposition to show the importance of new firms.

A second difference between our paper and KSW is in the way the price drop is interpreted. In general, a lower price could reflect higher productivity (lower marginal cost) or lower quality. ${ }^{2}$ To differentiate the two competing channels, ${ }^{3} \mathrm{KSW}$ isolate the "true" quality effect from price drops using a structural approach based on some assumptions on the demand structure, ${ }^{4}$ and compare it with the productivity distribution of firms estimated from a different set of data that cannot be satisfactorily matched to the trade data they use. ${ }^{5}$ Their conclusion is that productivity channel is the dominant mechanism behind the observed price drop. In this study, we take a different, reduced-form route by contrasting the size of price falls between homogeneous and heterogeneous products which are identified directly from the spread of price in the data or using external source of classification of product differentiation. While our finding lends support to the quality downgrading channel, we cannot rule out the productivity channel without reliable

\footnotetext{
${ }^{1}$ KSW reference our working paper in their 2013 journal publication (Khandelwal, Schott, and Wei, 2013) as well as their 2011 NBER working paper (Khandelwal, Schott, and Wei, 2011).

${ }^{2}$ Put more concisely, productivity would be negatively correlated with quality-adjusted price (e.g. Baldwin and Harrigan, 2011).

${ }^{3}$ These two channels are not necessarily mutually exclusive, and instead could be complements as in the endogenous quality choice model of Fan, Li, and Yeaple (2017).

${ }^{4}$ See Khandelwal (2010) for the development of this methodology.

${ }^{5} \mathrm{As} \mathrm{KSW}$ acknowledge, their firm productivity estimation is based on an external industrial survey that covers only a subset of the firms that engage in trade and contains no information about the firms' quota restrictiveness.
} 
production data on the firms.

The rest of the paper is organised as follows. Section 2 gives the institutional background of the MFA quota system. Section 3 describes the data used in this study. In section 4, we explain our research design and the empirical methodology involved. Results are presented in section 5, together with a battery of robustness checks regarding the definition of control and treatment groups and what constitutes a binding quota. Section 6 concludes.

\section{Institutional Background}

The Multifibre Arrangement (MFA) was the dominant international agreement for trade in textile and clothing products from the mid 1970s until the mid 1990s. It protected markets in developed countries from developing countries by restricting physical quantities of imports between pairs of importing and exporting countries. Central to the MFA were a series of bilateral agreements between large developed-country importers, such as the U.S. and E.U. countries, and developing-country exporters, such as Bangladesh, China, and India.

In 1995, the MFA was succeeded by a new agreement, the Agreement on Textiles and Clothing (ATC), as a result of the Uruguay Round talks. Under the ATC, countries reached bilateral agreements on how quotas were imposed and how they would be removed. Textile and clothing products ${ }^{6}$ were integrated into GATT/WTO rules under four phases $(1995,1998,2002$, and 2005), and each phase involved the removal of quotas on more products and an increase in the growth rates of remaining quotas. In the final phase, quotas were totally eliminated on January $1,2005$.

The U.S. is the second largest overseas market for Chinese textile exports. ${ }^{7}$ As China was not a member of WTO before 2001, it was initially not eligible for the ATC quota phaseouts.

\footnotetext{
${ }^{6}$ For simplicity, we use "textiles" to refer to "textiles and clothing" henceforth.

${ }^{7}$ Japan is the largest. If we treat Hong Kong as a separate overseas market for Chinese exports, then Hong Kong is the second largest overseas market. However, the great majority of these exports are subsequently re-exported to another destination. We do not consider these re-exports in this paper.
} 
However, after China entered the WTO at the end of 2001, it immediately enjoyed the first three stages of quota integration in the U.S. market in 2002 (Harrigan and Barrows, 2009). U.S. quotas on imports of Chinese textiles were then removed entirely on January 1, 2005. However, special safeguard mechanisms against Chinese textile imports remained in effect until December 31, 2008. These mechanisms allowed quotas to be reimposed if Chinese textile exports were believed to have harmed the market of the importing country (Yeung and Mok, 2004; Harrigan and Barrows, 2009). In the face of the huge increase in Chinese textile imports which occurred, some temporary quantity restrictions were set by the U.S. from the middle of $2005 .{ }^{8}$ According to a new memorandum reached by both countries in November 2005, these new quotas would remain in force for a three-year period until 2008.

While there were dramatic changes in the U.S. quotas on imports of textile products from China, it is worth noting that the U.S. Most-Favoured-Nations (MFN) tariffs for these products, which also applied to China after its WTO entry, remained fairly stable. In particular, from 2004 to 2005, all U.S. MFN tariffs on textiles remained almost unchanged. ${ }^{9}$ Specifically, when employing the World Integrated Trade Solution (WITS) tariff database we found that the average import tariff rate in China on three common raw materials of textiles — silk, wool, and cotton — remained almost constant (between 10.3\% and 10.4\%) from 2004 to 2006. This rules out the mechanisms proposed in Fan, Li, and Yeaple (2015) and guarantees that the MFA elimination was the only major policy shock on Chinese textile exports.

\footnotetext{
${ }^{8}$ Quotas were reimposed in May, August and November 2005 for different categories of goods.

${ }^{9}$ The information on U.S. tariffs can be found in the Tariff Database on the website of the United States International Trade Commission (USITC) at http://dataweb.usitc.gov/.
} 


\section{Data}

\subsection{Chinese customs trade statistics}

The data we use come from the transaction-level database of the Chinese Customs Trade Statistics (CCTS) which records, monthly: an 8-digit product code, a firm identification number, free-on-board value, physical quantity, and a destination country code. Since virtually all the MFA/ATC products fall in the Harmonised System (HS) chapters of textile and clothing products (chapters 50 to 63), we drop all the products outside these chapters. We select only those products covered by the MFA/ATC which were exported by Chinese firms to the U.S. market at some point between 2000 and 2006.

As well as exports by producers, the data also contain transactions by trading agents which mediate trade for other firms without producing the products themselves. The behaviour of trading firms could be very different from the behaviour of direct exporters (Ahn, Khandelwal, and Wei, 2011), and so we exclude these transactions from our analysis. ${ }^{10}$

The data are aggregated to the firm-product level for each year. Each row in the data is thus identified by a firm identifier $i$, an HS8 product code $j$ and year $t$.

\subsection{Identification of MFA/ATC products}

MFA/ATC products are identified at the 6-digit HS level from the Appendix of the ATC. ${ }^{11}$ Because HS codes are common across countries for the first 6-digits, we can identify these products

\footnotetext{
${ }^{10}$ Trading firms are identified by using certain keywords in their names. Manova and Zhang $(2009,2012)$ identified such firms for the period of 2000 to 2005, but they did not mention what these keywords were. Ahn, Khandelwal, and Wei (2011) used the Chinese characters meaning "importer", "exporter", and "trading" to identify the "intermediary firms". By contrast, we use our own, but more comprehensive list of keywords which are exclusively used by various kinds of trading agents in China. This list is available from the authors upon request.

${ }^{11}$ See Table A1 of Appendix A for the proportion of the MFA/ATC products in Chinese textile products exported to the U.S. in 2004. The full text of the ATC, including its Appendix, is available at the WTO webpage at http: //www.wto.org/english/docs_e/legal_e/16-tex_e.htm.
} 
precisely in our customs data. MFA/ATC products account for more than $92 \%$ of Chinese textile products exported to the U.S. We exclude the small number of textile products which are not covered by the MFA/ATC. ${ }^{12}$

\subsection{Identification of quota products}

The U.S. implemented quotas on Chinese textile products through the U.S. Office of Textile and Apparel (OTEXA), which listed, by year, detailed quota information. These quotas were implemented through 3-digit quota categories and each category contains multiple 10-digit HS codes, the most detailed HS level. ${ }^{13}$ The Chinese and U.S. HS systems are consistent only up to the first 6 digits, and so we aggregate our data to the 6-digit level. The great majority of 6-digit products fall into one or more OTEXA categories, and these are straightforwardly identified as quota products. ${ }^{14}$

\subsection{Calculation of fill rates}

The fill rate (or utilisation rate) is a widely used measure which indicates how restrictive a quota is during a given time period (normally a year). It is defined as the ratio of the actual quantity imported to the quota limit. In theory, quotas are binding only if the fill rate equals 1. In practice, for technical reasons, a quota is rarely fully filled, and the definition of a binding quota is somewhat subjective. ${ }^{15}$ In this study we follow the literature in assuming that a fill rate of 0.9 or above is binding, although in Section 5.2 we examine the effect of changing this

\footnotetext{
${ }^{12}$ Harrigan and Barrows (2009) and Brambilla, Khandelwal, and Schott (2010) also restrict their samples to MFA/ATC products.

${ }^{13}$ The concordance between OTEXA quota categories and 10-digit HS codes is available from OTEXA.

${ }^{14} \mathrm{~A}$ small number of 6-digit product categories contain some 10-digit products some which are covered by the OTEXA categories, and some of which are not. We also classify these as quota products, although their fill rate (see Section 3.4) will be lower as a result.

${ }^{15}$ The E.U. regards fill rates above 0.95 to be binding, while the United States International Trade Commission (USITC) use 0.9. Evans and Harrigan (2005) use a 0.9 fill rate as the threshold and this was adopted by both Harrigan and Barrows (2009) and Brambilla, Khandelwal, and Schott (2010).
} 
assumption. ${ }^{16}$

The calculation of fill rates for this study is complicated by the fact that the concordance between Chinese trade data and U.S. trade categories is only at the 6-digit level, and by the fact that the U.S. administered textile quotas through 3-digit OTEXA categories. A 6-digit product may fall in more than one quota category, and quota categories typically contain many 6-digit products. In principle, the fill rate for each 6-digit product $j$ at year $t$ in the U.S. market is simply $F_{j t}=Q_{j t} / \bar{Q}_{j t}$, where $Q_{j t}$ is the quantity exported and $\bar{Q}_{j t}$ is the quota imposed. However, we do not have direct information on either $Q_{j t}$ or $\bar{Q}_{j t}$ at the 6-digit level.

We can calculate $Q_{j t}$ by aggregating the the U.S. import quantity of each 10-digit product, $Q_{k t}$ from China by year. ${ }^{17}$ However, we cannot use the same method to calculate $\bar{Q}_{j t}$ because quota limits are set at much more aggregated 3-digit OTEXA category. We therefore assume that the fill rate for all 10-digit products within each quota category is constant. ${ }^{18}$ This gives us $F_{k t}$, which allows us to calculate $\bar{Q}_{k t}=Q_{k t} / F_{k t}$. Aggregating $\bar{Q}_{k t}$ to the 6-digit level gives us $\bar{Q}_{j t}$, which allows us to calculate $F_{j t}$ as required. In practice, this means that if all products within a 6-digit HS category fall in the same OTEXA 3-digit category, those products are all assigned the fill rate for that OTEXA category. If products within a 6-digit HS category fall in multiple OTEXA categories, the fill rate is a weighted averaged of the fill rates for each category.

\footnotetext{
${ }^{16}$ In some cases there were actually two layers of quotas. The first layer was simply a category-specific quota which was implemented through 3-digit OTEXA quota categories. All products within a category were subject to a common quantity limit. The second layer was a category-group quota which was imposed on multiple OTEXA quota categories within the category group. Some products were subject to quotas of both layers (See Brambilla, Khandelwal, and Schott (2010) for more details). For example, in 2001, products in OTEXA category 218 were subject to a category-specific limit of $12,565,591$ square metres, $91.0 \%$ of which was filled by the end of the year; but at the same time, they were also constrained by a category-group (GROUP-I which consisted of categories 210, 218,219 , etc.) limit of $1,506,349,283$ square metres, $85.1 \%$ of which was filled by the end of the year. In such cases, we take the maximum of the two fill rates ( $91.0 \%$ in the above example) as the actual fill rate of these products in that year.

${ }^{17}$ We obtained this information from the underlying data of Schott (2008), which is downloadable at Peter Schott's personal webpage at http://www.som. yale.edu/faculty/pks4/sub_international.htm.

${ }^{18}$ This is the same assumption used by Brambilla, Khandelwal, and Schott (2010).
} 


\section{Research Design}

The removal of quotas occurred abruptly on January 1, 2005, and our data covers the period both before and after that event. Products that had a binding quota in place in 2004 provide a "treatment" group, while products that did not have a binding quota in 2004 (or no quota at all) provide a "control" group. This naturally suggests a difference-in-differences (DD) comparison of the two groups. If the behaviour of products and firms in the control group represents the behaviour of those products and firms in the absence of the policy change, we can identify the causal impact of the policy change. One potential problem with this approach is that products in the control and treatment groups are potential substitutes in the U.S. market, and therefore quota changes could affect prices of the control group. In our robustness checks (Section 5.2) we therefore consider a comparison group from another country.

As a first step, we consider a product-level comparison, abstracting away the role of firms. Table 1 summarises the product-level information. In total, 580 separate 6-digit products were exported to the U.S. from China in 2004, and this increased to 661 in 2005. 446 of these products were subject to a quota in 2004, but only 137 were subject to a binding quota. The number of products subject to a quota falls sharply between 2004 and 2005, but by the end of 2005, 107 products had had quotas reimposed, of which 96 were binding.

We ignore products that had quotas re-imposed in 2005 (see Section 2), and we examine only products that were exported from China to the U.S. in both 2004 and 2005. Removing these products and defining treatment and control groups leads to the samples shown in the final two columns of Table 1. There are 98 products that had a binding quota in 2004 which was subsequently removed in 2005, and 374 products that either had no quota in 2004, or had a quota which was not binding. The products that fall in either the treatment or control groups comprised 66\% of the value of all textile exports to the U.S. in 2004.

The effect of quota removal on any product characteristic $y_{j t}$ can be estimated using a stan- 
dard multi-period DD equation:

$$
y_{j t}=\alpha+\rho D_{j}+\sum_{\substack{s=2000, s \neq 2004}}^{2006} \delta^{s} T_{t}^{s}+\sum_{\substack{s=2000, s \neq 2004}}^{2006} \lambda^{s}\left(T_{t}^{s} \times D_{j}\right)+\varepsilon_{j t} .
$$

We are particularly interested in the case where $y_{j t}$ is the product price, but we can also examine quantity and export value. $D_{j}$ is an indicator variable which takes the value 1 if a product $j$ is in the treatment group, and 0 otherwise, and which is a fixed characteristic of each product. $T_{t}^{s}$ is a year indicator which takes the value 1 if $t=s$ and 0 otherwise.

The constant $\alpha$ captures the average value of $y_{j t}$ for the control group in the base year, which is chosen to be 2004 , immediately before the quota removal. $\rho$ captures the difference in $y_{j t}$ between the treatment and control products in 2004, the $\delta^{s}$ capture the difference in $y_{j t}$ over time in the control group, and the $\lambda^{s}$ capture the difference in this difference between the treatment and control group. Thus, for example, if $\lambda^{2005}<0$, this indicates that prices of products in the treatment group fell relative to the change in prices in the control group between 2004 and 2005.

The choice of 2004 as the base year implies the estimate of $\lambda^{2005}$ removes the pre-existing difference in $y_{j t}$ between the treatment and control groups in 2004. If there are any pre-treatment effects on $y_{j t}$ this may be misleading. An advantage of our data is that we can use the estimates of $\lambda$ for years before 2004 to see if there are any pre-treatment differences in price movements.

As noted, equation (1) controls for the difference in $y_{j t}$ between the treatment and control group before quotas are removed. If we have a balanced panel of products, this pre-existing difference estimates the selection effect for all products in the comparison. However, Table 1 shows that neither the treatment nor the control group is balanced because some products are not exported to the U.S. in the years $2000, \ldots, 2003$ and 2006. In this case differences in $y_{j t}$ could be driven by the composition of products in each year. We can control for this by replacing the constant and the selection term $\left(\alpha+\rho D_{j}\right)$ with product fixed effects, $\alpha_{j}$. Estimates of $\lambda^{s}$ will 
now be identified by within product changes in $y_{j t}$, and cannot be the result of changes in the composition of products over time. Estimates of $\delta^{2005}$ and $\lambda^{2005}$ will be unaffected because the panel is balanced between those years.

The data also allow us to explore variations in the outcome variables at the firm-product level. That is, we can use $y_{i j t}$ rather than $y_{j t}$ as the dependent variable in Equation (1). This allows us to examine whether the effects of quota removal on prices are driven by a withinor a between-firm component. If changes in price are caused by new firms entering the export market, or by existing exporters exporting new products then the inclusion of firm fixed-effects will reduce the estimates of $\lambda^{2005}$. Even more precisely, the inclusion of firm-product fixed effects allows us to determine how much of the price drop comes from existing firms lowering prices of products that they exported before and after the quota removal.

Following Manova and Zhang (2012), it is also straightforward to consider the role of competition by including a firm-specific measure of market share in the estimate of $y_{i j t}$. Finally, one can estimate Equation (1) for different groups of products or firms and test whether $\lambda^{s}$ is equal across those groups.

\section{Results}

The extraordinarily large increase in the value of Chinese textile exports to the U.S. in our sample is illustrated in Figure 1. Between 2004 and 2005 previously quota-bound products (the treatment group) experienced a $155 \%$ growth in export value, while non-quota-bound products experienced a $61 \%$ growth. These values are somewhat larger than those reported by Harrigan and Barrows (2009) for U.S. imports of Chinese apparel and textiles in the same period. ${ }^{19}$

\footnotetext{
${ }^{19}$ Harrigan and Barrows (2009) estimate that the value of imports of Chinese apparel and textiles grew by $45 \%$. There are several possible reasons for the discrepancy between their estimate and ours. First, Harrigan and Barrows's (2009) sample includes all MFA/ATC products imported from China, while ours excludes trading firms. Second, our estimate is based on a restricted sample of products which fall clearly into a treatment or control group.
} 
In Figure 2 we plot the average unit values for the treatment and control groups. To make unit values comparable across products with different physical measurement units (e.g., kilograms and square metres), unit values are demeaned within each product. Figure 2 shows that unit values in the treatment group were somewhat higher than in the control group up to 2004, but unit values fell by over $0.3 \log$ points in the treatment group between 2004 and 2005, compared to a fall of about $0.1 \log$ points in the control group. This simple graphical comparison provides a clear illustration of the likely size of the effect of quota removal on unit values.

\subsection{Product-level analysis}

Table 2 summarises estimates of Equation (1) for export value $V_{j t}$, export quantity $Q_{j t}$ and unit values $P_{j t}=V_{j t} / Q_{j t}$. Columns (1), (3) and (5) report DD estimates (that is, without product fixed-effects). The estimate of $\delta^{2005}$ in column (1) shows that export values of the control group increased by $0.944 \log$ points (over 150\%) between 2004 and 2005 . The estimate of $\lambda^{2005}$ shows that exports of products in the treatment group increased in value by an additional 0.592 $\log$ points (another 80\%), and this additional effect is highly significant. Similar results are found for quantity (column 3), but the magnitudes are even larger.

The fact that increases in quantity are much greater than increases in export value imply that unit values must have fallen. This is shown in column (5). The estimate of $\rho=0.422$ shows that in 2004, unit values for products in the treatment group were significantly higher than in the control group. But the estimate of $\lambda^{2005}$ shows that unit values for products in the treatment group fell by $0.286 \log$-points (about 25\%) more than unit values in the control group between 2004 and 2005.20

We also report estimates of $\lambda^{2003}$ in Table 2. This parameter estimates the change in value, quantity and unit price between 2003 and 2004, the year before the quota removal. For all three

\footnotetext{
${ }^{20}$ This is slightly smaller, but very consistent with Harrigan and Barrows's (2009) finding for the price decrease, which is $32 \%$.
} 
outcomes the estimate is insignificantly different from zero. This is evidence that the trends in the characteristics of export products in the treatment and control groups were not significantly different in the pre-treatment period.

Columns (2), (4) and (6) in Table 2 show the results when we include product fixed-effects in Equation (1). As noted, because we have constructed a balanced panel of products between 2004 and 2005, the inclusion of fixed effects does not alter our estimates of $\delta^{2005}$ or $\lambda^{2005}$. However, outside those years the composition of products in the treatment and control groups may change. If lower unit-price products are more likely to remain in the treatment group compared to the control group, this could affect estimates of the quota effect in 2006. ${ }^{21}$ However, comparing the results between the DD and the FE specifications shows that $\lambda^{2006}$ is always very similar. Estimates of $\lambda^{2006}$ show that unit values continued to fall between 2005 and 2006, but the extent of the fall was much smaller than between 2004 and 2005, as we would expect.

\subsection{Robustness checks}

In this section we demonstrate that our basic result is robust to a number of modelling decisions which are somewhat arbitrary. First, we show that our results are robust to the level of product aggregation used. Second, we examine the effect of redefining the control group so that it includes only products which were not covered by quotas at all, rather than including products which were covered by non-binding quotas. Third, and as an extension of that, we examine the effect of changing the definition of a binding quota. Finally, we show that one can use a crosscountry comparison of price changes, rather than a within-country comparison, as we have done thus far. Estimates of $\lambda^{2005}$ for each of these robustness checks are reported in Table 3. The first row simply repeats the basic estimate from the product-level regression reported in Table 2.

The first issue is that the extent of the price fall could be affected by the level of classification

\footnotetext{
${ }^{21}$ This might also happen if the composition of products in terms of different measurement units changed over time, for example kilograms versus square metres.
} 
which we use to define a product. For any level of product classification, price changes will be determined both by price changes of particular varieties and changes in the composition of varieties within that classification. The more aggregate the classification, the greater the role for composition effects. As noted, we use HS6 classifications because HS codes are common across countries for the first 6-digits. However, to see to what extent our estimate is robust to the use of HS6 instead of more disaggregated product codes, we utilise an additional Chinese source of information, Quota-Restrained Textiles and HS Catalogue (Revised Version), an official guide book used by Chinese textile firms to precisely identify Chinese HS8 categories that are covered by the U.S. MFA quotas. This data allows us to compare quota products with non-quota products at a more narrowly defined product level. However, it is not possible with this data to identify fill rates precisely, so our treatment group is simply those products covered by MFA quotas in 2004 which were removed in 2005. The second row in Table 3 shows that even if we use more disaggregated HS codes and simply compare quota against non-quota products, we still find a sizeable and significant price drop of $-0.328 \log$ points. This suggests that the price change estimated by the base model is not greatly affected by the level of product classification we use.

Our second robustness check is to examine whether changing the precise definition of the treatment and control groups affects the magnitude of the price fall. In the base model the treatment group includes those products with a binding ( $>90 \%$ fill rate) quota, while the control group includes those products with no quota or with a non-binding quota. As noted in the introduction however, it is possible that even non-binding quotas had an effect on prices. For example, the allocation of quota licenses could still have prevented low-cost firms from exporting to the U.S. even if those quotas are not completely filled because these firms could not obtain licenses. Figure 3 plots the cumulative distribution of the fill rate for all 580 textile products sold by Chinese firms in the U.S. in 2004. 134 (23\%) of these products had no quota in 2004, and these are represented as having a fill rate of zero. Almost no quota products have a fill rate of less than $70 \%$, but a large fraction have fill rates between $70 \%$ and $90 \%$. 
The third row of Table 3 restricts the control group to include only non-quota products. The estimated price drop is now considerably larger at -0.371 . In rows (4) and (5) we expand the treatment group to include quota products with fill rates below $90 \%$ the estimated price drop falls. The results show that the drop in prices between 2004 and 2005 is systematically related to the fill rate. The largest price falls occurred for quota products with the highest fill rates, while the smallest price falls occurred for non-quota products. Thus the largest estimate of $\lambda^{2005}$ is found for the narrowest definition of the treatment and control groups, in row (3). Widening the definition of the treatment group reduces the estimated effect. These results show that the removal of quotas caused price falls even when those products did not face binding quotas. Hence, the removal of non-binding quotas from the control group causes the estimated price effect to become larger. Our results also show that the price falls were largest for those products which did face binding quotas, indicating that the fill rate mattered.

The final row of Table 3 deals with the concern that the treatment and control groups as defined are not independent because they both comprise textile products sold in the U.S. market. If products in the treatment and control groups are close substitutes, then large price changes in one group could affect demand and prices in the other group. Row (6) uses as a control group the same products as in the treatment group, but measures prices for those products sold to Japan rather than the U.S. These products are a suitable control group because quota arrangements between Japan and China did not change over the sample period. Estimated price falls are now $36 \%$ ( -0.441 log-points) and still highly significant. Thus, whether we compare the price falls of products within the U.S., or between the U.S. and Japan, we find that the removal of quotas had a large and significant effect on prices.

\subsection{Firm-product-level analysis}

Using product-level data, we have seen that the removal of quotas on January 1, 2005 caused a sudden large fall in unit prices of between $18 \%$ and $36 \%$. This finding is consistent with that 
observed for import data from the U.S. We now consider the role of firms in this price fall by using firm-product level data.

Table 4 reports our basic firm-product level results. In the first column of the top panel we re-estimate the basic DD model given by Equation (1), except that now we have data at the $i j t$ level rather than the $j t$ level. The estimate of -0.282 almost exactly reproduces the estimate of $\lambda^{2005}$ in Table 2. ${ }^{22}$ As before, because we have a balanced panel of products for 2004 and 2005, the inclusion of product fixed-effects has no effect on the estimate of $\lambda^{2005}$.

We are now also able to include fixed effects for each firm. Firm effects are important, as illustrated by the large increase in the explanatory power of the model: the $R^{2}$ increases from 0.696 to 0.901 . The estimate of $\lambda^{2005}$ falls substantially to -0.171 , indicating an important role for firms in the observed fall in unit values. The model which includes product and firm fixedeffects controls for changes in the identity of products and firms in the treatment and control group. So the fall in the size of $\lambda^{2005}$ tells us that a large fraction of the fall in unit values is driven by changes in the identity of firms which were exporting products in the treatment group. In other words, the entry and exit of firms into the U.S. export market. Several authors have documented how the Chinese export boom has been driven by the entry of new firms to the export market (e.g. Manova and Zhang, 2009; Upward, Wang, and Zheng, 2013; Khandelwal, Schott, and Wei, 2013), and this is borne out by these results. Essentially, the within-firm fall in unit values was much smaller than the total fall in unit values.

In the final column we include fixed effects for each firm-product combination. In this model $\lambda^{2005}$ is identified only by changes in unit values of a particular firm-product combination, which might be thought of as a particular variety of that product. There are 80,590 firm-product combinations in the data, compared to 19,093 firms and 472 products, so this model has many

\footnotetext{
${ }^{22}$ To reproduce the product-level results we need to weight by the share of export value accounted for by each firmproduct combination. To see this, note that, in the product-level regression, each observation $j$ is a sum over all firms exporting $j$, which means that firms exporting larger quantities are given a greater weight. In the firm-product-level regression each observation is a firm-product combination and each has an equal weight. Weighting by the share of export value resolves this problem. The very slight discrepancy between the product-level and the firm-product level estimate is due to a log approximation.
} 
more parameters. As a result there is another large increase in the explanatory power of the model. The estimate of $\lambda^{2005}(-0.147)$ is now only half the size of the product-FE estimate. The fall in the size of the coefficient from column (2) to column (4) suggests that about half the fall in the price came about through a combination of new exporting firms and new exporting products. Indeed, we cannot reject the hypothesis that there was no fall in prices among existing firm-product combinations, but this coefficient is imprecisely estimated.

In the bottom panel of Table 4 we also include a variable for product-market competition to control for the potential impact of competition on prices. ${ }^{23}$ This is measured by the firm's share in the exports of each product to the U.S. market. The coefficient on market share is positive and significant in all fixed-effects specifications, indicating that a larger market share allows firms to charge higher prices. Nevertheless, the inclusion of market shares has only a relatively small effect on the quota removal parameter. ${ }^{24}$

\subsection{Price falls by type of product}

In this section we examine which types of products experienced the largest falls in unit value in order to measure the importance of the quality downgrading hypothesis. We start from the assumption that a homogeneous product with a fixed set of characteristics cannot by definition change its quality, and therefore changes in the price of such a product must represent changes in mark-ups rather than changes in quality. ${ }^{25}$ In contrast, a product which is more heterogeneous may differ in terms of its characteristics either over time or between producers. Changes in the prices of these products will represent both changes in mark-ups and also changes in characteristics, or quality.

\footnotetext{
${ }^{23}$ See Antoniades (2015) for a recent heterogeneous-firms trade model that highlights firms' endogenous quality choice and endogenous mark-ups in response to market competition.

${ }^{24}$ A DD regression of market share shows a monotonic fall in market share from 2000 to 2006, but only small differences in this fall between products in the treatment and control group.

${ }^{25}$ Some raw materials in the HS chapter of textiles can be considered as perfectly homogeneous products, e.g., HS 500100 "Silk-worm Cocoons Suitable for Reeling".
} 
We do not have a precise measure of product heterogeneity. As a proxy, we use the variance of product price in 2004 . We classify products with a price variance above the median to be heterogeneous, and products with a price variance below the median to be homogeneous. ${ }^{26}$ Clearly such a classification is only an approximation, but nevertheless provides a lower-bound on the size of the quality effect over and above the competition effect. However, one problem with this classification is that the variance of product price partly reflects the number of firms which sell the product. We therefore also categorise products according to their residual price variance after controlling for the number of firms that sell that product. In Table 5 we show how our measure of product heterogeneity, based on price variance, varies across the different categories of product used by Rauch (1999). As we would expect, the largest price variation is in clothing products, all of which are classified by Rauch's measure as differentiated products. Price variance is smaller for textiles, and within textiles price variance is smaller for reference-priced products and smallest for a small number of textiles which are exchange-traded. These pattern is consistent whether or not we control for the number of producers of each product. This provides some support for the idea that pre-existing price variance captures product heterogeneity.

We then estimate Equation (1) for high- and low-price variance products. Results are reported in Table 6 . The estimate of $\lambda^{2005}$ is negative and significantly different from zero for both types of product, indicating unit value falls in homogeneous and heterogeneous products. However, $\lambda^{2005}$ is estimated to be more than twice as large for heterogeneous products. If the price drop for homogeneous products is assumed to be only a competition effect, this suggests that the quality effect is a large component of the total price effect. In practice, there is also heterogeneity among those products in the homogeneous group because these products have non-zero price variance in 2004 . Therefore the quality effect estimated is probably a lower bound. This result lends support to the notion that quality downgrading played an important role in the price drop.

\footnotetext{
${ }^{26}$ We can also classify products using other percentiles in the standard deviation of price as thresholds. As we would expect, widening the threshold (for example using the 25th and 75th percentile) causes the result to become more pronounced.
} 


\section{Conclusions}

This study provides an empirical assessment of the effect of quota restrictions on exporting firms. To that end, we use a unique and comprehensive firm-product-destination level data set of Chinese textile and clothing firms to examine how they actually responded to the elimination of the MFA/ATC quotas on January 1, 2005 in the U.S. market. Three features of our data make the identification of the quota effects possible and convincing. First, the event of the MFA/ATC quota removal was large-scale and clear-cut in terms of timing and product coverage. Second, a linkage is built by us between the U.S. import quotas and Chinese textile and clothing products at a very disaggregated level. Third, our firm-product-level data allows us to examine price changes within and across firms and products.

By employing a difference-in-differences estimation strategy, we find an average price drop of about $25 \%$ due to the removal of the MFA/ATC quotas. We demonstrate that this price drop occurred exactly as the quotas were removed; price changes in the year before removal were similar for treatment and control products. We then show that the estimated price drop varies in systematic ways depending on how widely the control and treatment products are defined. We also show that the price drop remains large and significant whether or not the comparison is conducted across products within a destination market, or within products across destination markets. Of this overall drop in price, more than half was found to be caused by the entrance of new low-price firms and new low-price products. Finally, we show that the price fall was significantly larger for products whose initial price variance was larger, which we interpret as "heterogeneous products".

Overall, our results demonstrate that the findings of $\mathrm{HB}$ can be replicated using entirely different data from the exporters' rather than the importers' side, and also that these findings are robust to a number of different definitions of control and treatment products. In particular, our finding of a larger price drop for heterogeneous than for homogeneous products is compatible with the quality downgrading effects identified by HB. Our results also demonstrate that the 
findings of KSW can be replicated using a different and simpler identification strategy. 


\section{References}

Ahn, J., A. K. Khandelwal, And S.-J. Wei (2011): “The Role of Intermediaries in Facilitating Trade," Journal of International Economics, 84(1), 73-85.

AnTONIADES, A. (2015): “Heterogeneous Firms, Quality, and Trade,” Journal of International Economics, 95(2), 263-273.

BAlDwin, R. AND J. HARRIGAN (2011): "Zeros, Quality, and Space: Trade Theory and Trade Evidence," American Economic Journal: Microeconomics, 3(2), 60-88.

Bernhofen, D., R. Upward, AND Z. WANG (2011): “Quota as a Sorting Machine: Quantity Restrictions and Price Adjustment of Chinese Textile Exports to the U.S." Working Paper, University of Nottingham.

Brambilla, I., A. Khandelwal, and P. Schott (2010): “China's Experience Under the Multifiber Arrangement (MFA) and the Agreement on Textiles and Clothing (ATC)," in China's Growing Role in World Trade, Ed. by R. Feenstra and S.-J. Wei, Chicago: University of Chicago Press.

Evans, C. And J. Harrigan (2005): “Tight Clothing. How the MFA Affects Asian Apparel Exports," in International Trade in East Asia, Ed. by T. Ito and A. K. Rose, Chicago: University of Chicago Press, Vol. 14 of NBER-East Asia Seminar on Economics, 367-390.

FalveY, R. E. (1979): “The Composition of Trade within Import-Restricted Product Categories," Journal of Political Economy, 87(5), 1105-1114.

FAn, H., Y. A. LI, AND S. R. YeaPle (2015): “Trade Liberalization, Quality, and Export Prices," Review of Economics and Statistics, 97(5), 1033-1051.

_ (2017): “On the Relationship Between Quality and Productivity: Evidence from China's Accession to the WTO," Working Paper. 
HARrigan, J. AND G. BARRows (2009): “Testing the Theory of Trade Policy: Evidence from the Abrupt End of the Multifiber Arrangement," Review of Economics and Statistics, 91(2), 282-294.

Khandelwal, A. (2010): “The Long and Short (of) Quality Ladders," Review of Economic Studies, 77(4), 1450-1476.

Khandelwal, A. K., P. K. Schott, And S.-J. Wei (2011): “Trade Liberalization and Embedded Institutional Reform: Evidence from Chinese Exporters,” NBER Working Paper No. 17524.

_ (2013): "Trade Liberalization and Embedded Institutional Reform: Evidence from Chinese Exporters," American Economic Review, 103(6), 2169-95.

MANOVA, K. AND Z. ZHANG (2009): “China's Exporters and Importers: Firms, Products and Trade Partners,” NBER Working Paper No. 15249.

(2012): “Export Prices across Firms and Destinations," Quarterly Journal of Economics, 127(1), 379-436.

RAUCH, J. E. (1999): “Networks versus markets in international trade," Journal of international Economics, 48(1), 7-35.

Schotт, P. K. (2008): “The Relative Sophistication of Chinese Exports," Economic Policy, 23(1), 5-49.

UpwARD, R., Z. WANG, AND J. Zheng (2013): "Weighing China's Export Basket: The Domestic Content and Technology Intensity of Chinese Exports," Journal of Comparative Economics, 41(2), 527-543.

Yeung, G. AND V. MoK (2004): "Does WTO Accession Matter for the Chinese Textile and Clothing Industry?" Cambridge Journal of Economics, 28(6), 937-954. 
Figures

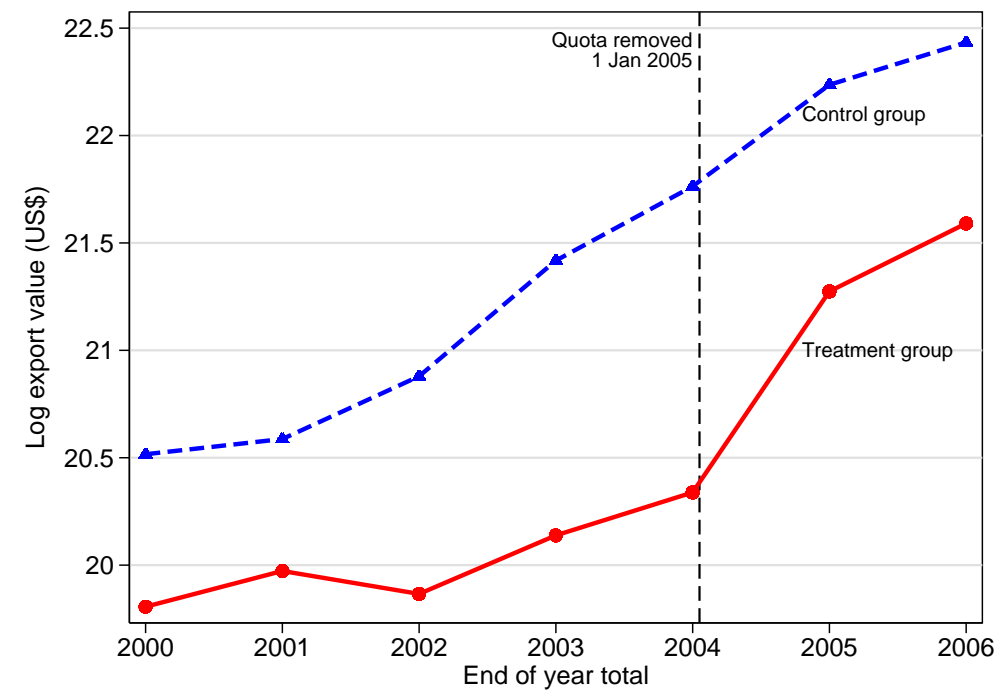

Figure 1. Log total value of MFA/ATC textile products exported from China to U.S. 2000-2006. Treatment and control groups are those defined in Table 1. 


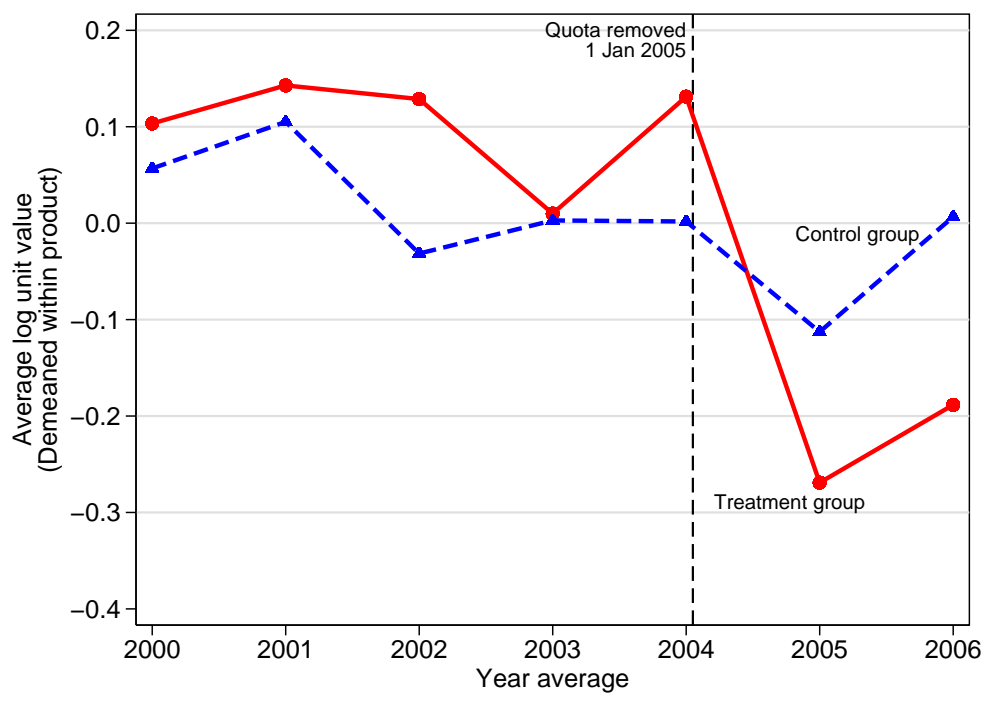

Figure 2. Log unit value of MFA/ATC textile products exported from China to U.S. 2000-2006. Treatment and control groups are those defined in Table 1. 


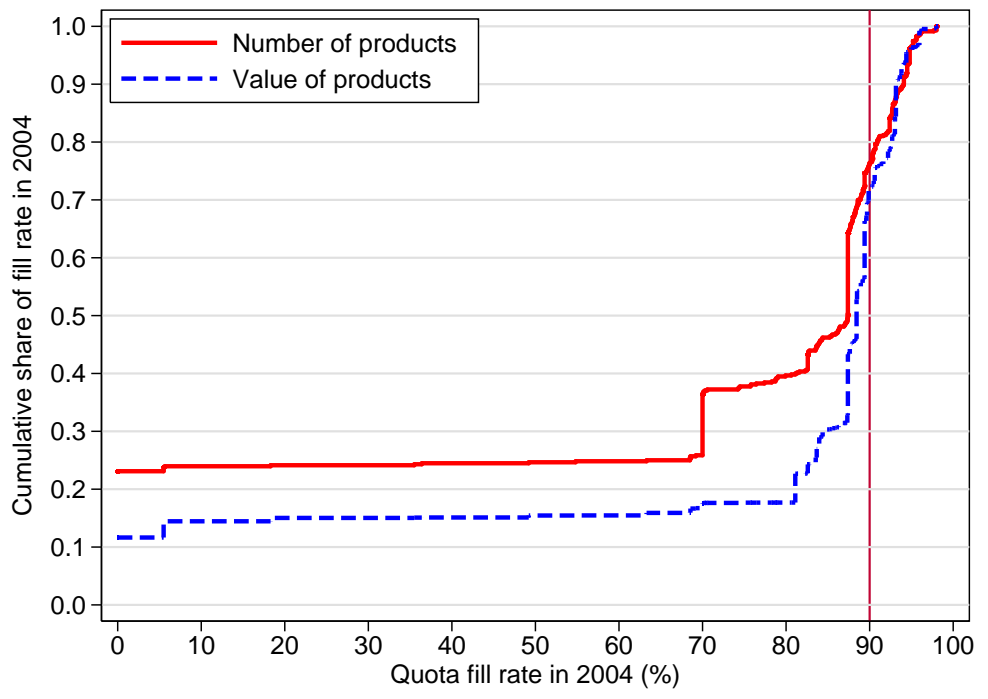

Figure 3. Cumulative distribution of the fill-rate, 2004. Sample includes all 580 6-digit textile products exported to the U.S. from China in 2004. Products with no quota are given a fill-rate of zero. 


\section{Tables}

Table 1. Numbers of MFA/ATC products

\begin{tabular}{|c|c|c|c|c|c|c|c|}
\hline \multirow{2}{*}{ Year } & \multirow{2}{*}{$\begin{array}{c}\text { All } \\
\text { products }\end{array}$} & \multicolumn{2}{|c|}{$\begin{array}{c}\text { Subject to U.S. } \\
\text { quotas }\end{array}$} & \multicolumn{2}{|c|}{$\begin{array}{l}\text { Subject to U.S. } \\
\text { binding quotas }\end{array}$} & \multirow[t]{2}{*}{ Treatment } & \multirow[t]{2}{*}{ Control } \\
\hline & & No & Yes & No & Yes & & \\
\hline 2000 & 504 & 33 & 471 & 236 & 268 & 75 & 295 \\
\hline 2001 & 515 & 35 & 480 & 380 & 135 & 82 & 300 \\
\hline 2002 & 541 & 40 & 501 & 471 & 70 & 87 & 322 \\
\hline 2003 & 575 & 46 & 529 & 460 & 115 & 93 & 344 \\
\hline 2004 & 580 & 134 & 446 & 443 & 137 & 98 & 374 \\
\hline 2005 & 661 & 554 & 107 & 565 & 96 & 98 & 374 \\
\hline 2006 & 656 & 477 & 179 & 656 & 0 & 96 & 366 \\
\hline
\end{tabular}

NOTE. - Products are 6-digit HS products in chapters 50-63 (textiles and clothing), which are covered by the MFA/ATC, and which are exported from China to the U.S. in that year. "Binding quotas" are quotas with fill rates greater than $90 \%$. The calculation of fill rates is explained in Section 3.4. An exception is the year 2005, in which quotas were reimposed on some products from May onwards, and the fill rates are calculated based on periods shorter than seven months instead of a whole calendar year. The treatment group are products subject to binding quotas in 2004 which do not have quotas in 2005. The control group are products not subject to quotas or subject to non-binding quotas in 2004 and which do not have quotas in 2005 . 
Table 2. Product-level estimates of quota effect using Equation (1)

\begin{tabular}{|c|c|c|c|c|c|c|}
\hline & \multicolumn{2}{|c|}{ Value: $\ln \mathrm{V}_{j t}$} & \multicolumn{2}{|c|}{ Quantity: $\ln \mathrm{Q}_{j t}$} & \multicolumn{2}{|c|}{ Unit value: $\ln \mathrm{P}_{j t}$} \\
\hline & (1) DD & (2) Prod. FE & (3) DD & (4) Prod. FE & (5) DD & (6) Prod. FE \\
\hline$\rho$ & $\begin{array}{c}0.483 \\
(0.325)\end{array}$ & & $\begin{array}{c}0.061 \\
(0.325)\end{array}$ & & $\begin{array}{l}0.422^{\text {*** }} \\
(0.116)\end{array}$ & \\
\hline$\delta^{2000}$ & $\begin{array}{c}-0.417^{* *} \\
(0.146)\end{array}$ & $\begin{array}{c}-1.022^{* * *} \\
(0.144)\end{array}$ & $\begin{array}{c}-0.517^{* *} \\
(0.158)\end{array}$ & $\begin{array}{c}-1.081^{* * *} \\
(0.157)\end{array}$ & $\begin{array}{c}0.099 \\
(0.053)\end{array}$ & $\begin{array}{c}0.060 \\
(0.049)\end{array}$ \\
\hline$\delta^{2001}$ & $\begin{array}{c}-0.514^{* * *} \\
(0.145)\end{array}$ & $\begin{array}{c}-1.095^{* * *} \\
(0.132)\end{array}$ & $\begin{array}{c}-0.594^{* * *} \\
(0.166)\end{array}$ & $\begin{array}{c}-1.203^{* * *} \\
(0.152)\end{array}$ & $\begin{array}{c}0.080 \\
(0.054)\end{array}$ & $\begin{array}{c}0.109^{*} \\
(0.050)\end{array}$ \\
\hline$\delta^{2002}$ & $\begin{array}{c}-0.093 \\
(0.114)\end{array}$ & $\begin{array}{c}-0.549^{* * *} \\
(0.102)\end{array}$ & $\begin{array}{c}-0.060 \\
(0.125)\end{array}$ & $\begin{array}{c}-0.517^{\text {*** }} \\
(0.112)\end{array}$ & $\begin{array}{c}-0.032 \\
(0.048)\end{array}$ & $\begin{array}{r}-0.031 \\
(0.045)\end{array}$ \\
\hline$\delta^{2003}$ & $\begin{array}{c}0.139 \\
(0.101)\end{array}$ & $\begin{array}{r}-0.105 \\
(0.089)\end{array}$ & $\begin{array}{c}0.157 \\
(0.112)\end{array}$ & $\begin{array}{c}-0.108 \\
(0.096)\end{array}$ & $\begin{array}{c}-0.018 \\
(0.040)\end{array}$ & $\begin{array}{c}0.002 \\
(0.039)\end{array}$ \\
\hline 005 & $\begin{array}{c}0.944^{* * *} \\
(0.085)\end{array}$ & $\begin{array}{l}0.944^{* * *} \\
(0.093)\end{array}$ & $\begin{array}{l}1.059^{* * *} \\
(0.091)\end{array}$ & $\begin{array}{l}1.059^{* * *} \\
(0.099)\end{array}$ & $\begin{array}{c}-0.115^{* * *} \\
(0.032)\end{array}$ & $\begin{array}{c}-0.115^{* *} \\
(0.035)\end{array}$ \\
\hline$\delta^{2006}$ & $\begin{array}{l}1.395^{* * *} \\
(0.096)\end{array}$ & $\begin{array}{l}1.328^{* * *} \\
(0.103)\end{array}$ & $\begin{array}{l}1.388^{* * *} \\
(0.106)\end{array}$ & $\begin{array}{l}1.323^{* * *} \\
(0.114)\end{array}$ & $\begin{array}{c}0.007 \\
(0.036)\end{array}$ & $\begin{array}{c}0.005 \\
(0.038)\end{array}$ \\
\hline$\lambda^{2000}$ & $\begin{array}{c}0.580 \\
(0.339)\end{array}$ & $\begin{array}{c}0.291 \\
(0.299)\end{array}$ & $\begin{array}{c}0.581 \\
(0.331)\end{array}$ & $\begin{array}{c}0.365 \\
(0.293)\end{array}$ & $\begin{array}{c}-0.001 \\
(0.093)\end{array}$ & $\begin{array}{c}-0.075 \\
(0.082)\end{array}$ \\
\hline$\lambda^{2001}$ & $\begin{array}{c}0.704^{*} \\
(0.277)\end{array}$ & $\begin{array}{c}0.646^{* *} \\
(0.228)\end{array}$ & $\begin{array}{c}0.710^{*} \\
(0.287)\end{array}$ & $\begin{array}{c}0.731^{* *} \\
(0.242)\end{array}$ & $\begin{array}{c}-0.005 \\
(0.093)\end{array}$ & $\begin{array}{r}-0.086 \\
(0.087)\end{array}$ \\
\hline$\lambda^{20}$ & $\begin{array}{c}0.079 \\
(0.218)\end{array}$ & & $\begin{array}{c}0.023 \\
(0.227)\end{array}$ & & $\begin{array}{c}0.056 \\
(0.070)\end{array}$ & $\begin{array}{l}0.037 \\
(0.068)\end{array}$ \\
\hline$\lambda^{2003}$ & $\begin{array}{c}-0.203 \\
(0.220)\end{array}$ & $\begin{array}{c}-0.158 \\
(0.200)\end{array}$ & $\begin{array}{c}-0.095 \\
(0.216)\end{array}$ & $\begin{array}{c}-0.037 \\
(0.191)\end{array}$ & $\begin{array}{c}-0.108 \\
(0.077)\end{array}$ & $\begin{array}{c}-0.121 \\
(0.076)\end{array}$ \\
\hline 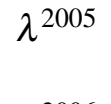 & $\begin{array}{c}0.592^{* *} \\
(0.195)\end{array}$ & $\begin{array}{c}0.592^{* *} \\
(0.213)\end{array}$ & $\begin{array}{l}0.878^{* * *} \\
(0.211)\end{array}$ & $\begin{array}{l}0.878^{* * *} \\
(0.230)\end{array}$ & $\begin{array}{c}-0.286^{* * *} \\
(0.062)\end{array}$ & $\begin{array}{c}-0.286^{* *} \\
(0.068)\end{array}$ \\
\hline$\lambda^{2006}$ & $\begin{array}{c}0.570^{* *} \\
(0.203)\end{array}$ & $\begin{array}{c}0.571^{* *} \\
(0.217)\end{array}$ & $\begin{array}{l}0.900^{* * *} \\
(0.221)\end{array}$ & $\begin{array}{l}0.895^{* * *} \\
(0.238)\end{array}$ & $\begin{array}{c}-0.330^{* * *} \\
(0.069)\end{array}$ & $\begin{array}{c}-0.324^{* *} \\
(0.075)\end{array}$ \\
\hline$R^{2}$ & 0.077 & 0.807 & 0.071 & 0.802 & 0.018 & 0.863 \\
\hline$J$ & & 472 & 472 & 472 & 472 & 472 \\
\hline$N$ & 3,003 & 3,003 & 3,003 & 3,003 & 3,003 & 3,003 \\
\hline
\end{tabular}

Note. - Products are defined at the 6-digit level. The treatment and control groups are those defined in Table 1. Standard errors are clustered at the 6-digit product level. Statistical significance indicated by * $(5 \%),{ }^{* *}(1 \%)$ and ${ }^{* * *}$ $(0.1 \%) . J$ indicates number of products, and $N$ is total sample size. 
Table 3. Robustness checks

\begin{tabular}{|c|c|c|c|}
\hline & $\begin{array}{c}J \\
\text { (treatment) }\end{array}$ & $\begin{array}{c}J \\
\text { (control) }\end{array}$ & $\lambda^{2005}$ \\
\hline $\begin{array}{l}\text { (1) Base model } \\
\text { (quota-bound vs. quota-unbound and } \\
\text { non-quota products) }\end{array}$ & 98 & 374 & $\begin{array}{l}-0.286^{* * *} \\
(0.062)\end{array}$ \\
\hline $\begin{array}{l}\text { (2) 8-digit product codes } \\
\text { (quota vs. non-quota products) }\end{array}$ & 326 & 61 & $\begin{array}{l}-0.328^{* * *} \\
(0.074)\end{array}$ \\
\hline $\begin{array}{l}\text { (3) Narrower control group } \\
\text { (includes only non-quota products) }\end{array}$ & 98 & 127 & $\begin{array}{l}-0.371^{* * *} \\
(0.078)\end{array}$ \\
\hline $\begin{array}{l}\text { (4) Wider treatment group } \\
\text { (includes products with fill rate } \geq 80 \% \text { ) }\end{array}$ & 267 & 127 & $\begin{array}{l}-0.231^{* * *} \\
(0.066)\end{array}$ \\
\hline $\begin{array}{l}\text { (5) Wider treatment group } \\
\text { (includes all quota products) }\end{array}$ & 345 & 127 & $\begin{array}{c}-0.197^{* *} \\
(0.065)\end{array}$ \\
\hline $\begin{array}{l}\text { (6) U.S. vs. Japan } \\
\text { (U.S. quota-bound products) }\end{array}$ & 98 & 88 & $\begin{array}{l}-0.441^{* * *} \\
(0.064)\end{array}$ \\
\hline
\end{tabular}

NOTE. - The first two columns give the number of products in the treatment and control groups respectively. The third column reports the estimated change in unit values from Equation (1). $J$ indicates number of products. 
Table 4. Firm-product-level estimates of quota effect using Equation (1)

\begin{tabular}{ccccc}
\hline (1) & $(2)$ & $(3)$ & $(4)$ \\
& Firm FE + & Firm- \\
DD & Prod. FE & prod. FE & prod. FE \\
\hline
\end{tabular}

(a) Without controls for market share

$\begin{array}{lcccc}\lambda^{2005} & -0.282^{* * *} & -0.282^{* * *} & -0.171^{* * *} & -0.147 \\ & (0.065) & (0.065) & (0.047) & (0.080) \\ R^{2} & 0.019 & 0.696 & 0.901 & 0.983\end{array}$

(b) With controls for market share

$\begin{array}{lcccc}\lambda^{2005} & -0.273^{* * *} & -0.268^{* * *} & -0.162^{* * *} & -0.142 \\ & (0.064) & (0.065) & (0.045) & (0.079) \\ \text { Market share } & 0.532^{* * *} & 0.840^{* * *} & 0.415^{* * *} & 0.161^{*} \\ & (0.122) & (0.059) & (0.038) & (0.063) \\ R^{2} & 0.037 & 0.716 & 0.903 & 0.983 \\ & & & & \\ J & 472 & 472 & 472 & 472 \\ N & 124,370 & 124,370 & 124,370 & 124,370\end{array}$

NOTE. - The dependent variable is $\log$ unit value $\ln \left(P_{i j t}\right)$. Products are defined at the 6-digit level. Results are weighted by the share of export value accounted for by each firm-product combination. The treatment and control groups are those defined in Table 1. Standard errors are clustered at the 6-digit product level. Statistical significance indicated by ${ }^{*}(10 \%),{ }^{* *}$ $(5 \%)$ and ${ }^{* * *}(1 \%)$. Market share is measured as the proportion of exports accounted for by that firm-product-year combination. $J$ indicates number of products, and $N$ is total sample size. 
Table 5. Price variance across different product categories

\begin{tabular}{lrcc}
\hline & $\begin{array}{c}\text { No. of } \\
\text { products }\end{array}$ & $\begin{array}{c}\text { Mean } \\
\text { price variance } \\
\text { in 2004 }\end{array}$ & $\begin{array}{c}\text { Mean residual }^{\text {a }} \\
\text { price variance } \\
\text { in 2004 }\end{array}$ \\
\hline (a) Textile products & 191 & 0.607 & -0.028 \\
Differentiated products & 90 & 0.393 & -0.227 \\
Reference-priced products & 12 & 0.133 & -0.483 \\
Products traded on an organized exchange & & & \\
(b) Clothing & 179 & 0.923 & - \\
Differentiated products & 0 & - & - \\
Reference-priced products & 0 & - & - \\
Products traded on an organized exchange & 0.209 \\
\hline
\end{tabular}

Note. - The three categories are those defined by Rauch (1999).

${ }^{a}$ Residual after controlling for number of firms producing each product.

Table 6. Estimates of Equation (1) separately for homogeneous and heterogeneous products, as defined by variance of price in 2004

\begin{tabular}{|c|c|c|c|}
\hline & $\begin{array}{r}\text { Homogeneous } \\
\text { products }\end{array}$ & $\begin{array}{r}\text { Heterogeneous } \\
\text { products }\end{array}$ & Difference \\
\hline \multicolumn{4}{|c|}{ (a) Based on $\sigma_{P}$ in 2004} \\
\hline$\lambda^{2005}$ & $\begin{array}{c}-0.187^{* *} \\
(0.086)\end{array}$ & $\begin{array}{c}-0.391^{\text {*** }} \\
(0.089)\end{array}$ & $\begin{array}{r}-0.203 \\
(0.124)\end{array}$ \\
\hline$J$ & 242 & 230 & \\
\hline$N$ & 1,472 & 1,531 & \\
\hline \multicolumn{4}{|c|}{ (b) Based on $\sigma_{P}$ in 2004, conditional on number of firms } \\
\hline$\lambda^{2005}$ & $\begin{array}{r}-0.161^{*} \\
(0.085)\end{array}$ & $\begin{array}{c}-0.422^{* * *} \\
(0.091)\end{array}$ & $\begin{array}{r}-0.261^{* *} \\
(0.124)\end{array}$ \\
\hline$J$ & 241 & 231 & \\
\hline$N$ & 1,471 & 1,532 & \\
\hline
\end{tabular}

NOTE. - Standard errors are clustered at the 6-digit product level. Statistical significance indicated by ${ }^{*}(10 \%),{ }^{* *}(5 \%)$ and ${ }^{* * *}(1 \%) . J$ indicates number of products, and $N$ is total sample size. 


\section{Appendix A Additional tables}

Table A1. Chinese textile and clothing products exported to the U.S. and their MFA/ATC Status, 2004 (HS 50-63, CCTS Data)

\begin{tabular}{llrrr}
\hline HS & Product & $\begin{array}{r}\text { No. of } \\
\text { MFA/ATC } \\
\text { products }\end{array}$ & $\begin{array}{r}\text { No. of } \\
\text { other } \\
\text { products }\end{array}$ & $\begin{array}{r}\text { Value of } \\
\text { products (\%) }\end{array}$ \\
\hline 50 & Description & 6 & 2 & 99.9 \\
51 & Wilk & 14 & 3 & 92.6 \\
52 & Coolt, fine/coarse animal hair, horsehair yarn \& fabrics & 73 & 2 & 97.1 \\
53 & Other vegetable textile fibres; paper yarn \& woven fabrics & 11 & 0 & 100.0 \\
54 & Man-made filaments & 42 & 4 & 90.1 \\
55 & Man-made staple fibres & 70 & 1 & 99.9 \\
56 & Wadding, felt \& nonwoven; yarns; twine, cordage, etc. & 23 & 8 & 54.7 \\
57 & Carpets and other textile floor coverings & 20 & 1 & 81.9 \\
58 & Special woven fabrics; tufted tex fabrics; lace; tapestries & 35 & 2 & 99.2 \\
& etc. & & & \\
59 & Impregnated, coated, cover/laminated textile fabric etc. & 22 & 1 & 100.0 \\
60 & Knitted or crocheted fabrics & 6 & 30 & 3.0 \\
61 & Art. of apparel \& clothing access, knitted or crocheted & 96 & 11 & 90.5 \\
62 & Art. of apparel \& clothing access, not knitted/crocheted & 110 & 6 & 96.3 \\
63 & Other made up textile articles; sets; worn clothing etc. & 52 & 7 & 88.1 \\
& & & & 91.6 \\
\hline $50-63$ & All & 580 & 78 & \\
\hline
\end{tabular}

